\title{
63. Synthesis of N-Phenylacetylphenylalanineamide from Phenylpyruvate and Ammonium Sulfate in Aqueous Medium
}

\author{
By Fujio Egami, Yumiko Makino, Kazuki Sato, \\ and Masato NishizaWA \\ Mitsubishi-Kasei Institute of Life Sciences, Machida, Tokyo 194 \\ (Communicated by Shiro Akabori, M. J. A., Nov. 12, 1981)
}

For the last few years, we have been engaged in the synthesis of amino acids in aqueous medium as a model for prebiotic synthesis in chemical evolution.1),2) In course of our study, we discovered a novel method for the synthesis of amino acids and $\mathrm{N}$-acylamino acids in an aqueous medium. ${ }^{3)}$ Glycine and alanine were produced from glyoxylate and pyruvate respectively in an ammonium sulfate solution through $\mathrm{N}$-acylamino acids as follows:

$$
\begin{aligned}
& 2 \text { glyoxylate }+\mathrm{NH}_{3} \underset{\mathrm{H}_{3} \mathrm{O}^{+}}{\longrightarrow} \text { oxalate }+ \text { Gly } \\
& 2 \text { pyruvate }+\mathrm{NH}_{3} \stackrel{\stackrel{\mathrm{H}_{3} \mathrm{O}^{+}}{\longrightarrow} \mathrm{CO}_{2}+\mathrm{N} \text {-acetylalanine }}{\longrightarrow} \text { acetate }+ \text { Ala. }
\end{aligned}
$$

This paper deals with the synthesis of N-phenylacetylphenylalanineamide by a similar process.

An aqueous solution ( $50 \mathrm{ml}, \mathrm{pH} \mathrm{6}$ ) of sodium phenylpyruvate $(0.5 \mathrm{M})$ and ammonium sulfate $(0.25 \mathrm{M})$ was put into a round-bottomed flask equipped with a condenser and maintained at $90^{\circ} \mathrm{C}$ for $24 \mathrm{hr}$ in a silicon oil bath. After standing at room temperature, the resulting precipitates were filtered and recrystalized from methanol (m.p. $190^{\circ}-191^{\circ} \mathrm{C}$ ). The supernatant was lyophilized, hydrolyzed with $6 \mathrm{M} \mathrm{HCl}$ and subjected to amino acid analysis. The hydrolyzate of purified needle crystals yielded phenylalanine in 40 weight percent of obtained product.

Elemental analysis showed the following: $\mathrm{C}, 72.18 ; \mathrm{H}, 6.45$ and $\mathrm{N}, 9.89 \%$. This corresponds to the formula $\mathrm{C}_{17} \mathrm{H}_{18} \mathrm{~N}_{2} \mathrm{O}_{2}$. The IR ( $\mathrm{KBr}$ disc) spectrum is shown in Fig. 1, and secondary amide absorptions were 3170,1660 and $1640 \mathrm{~cm}^{-1}$. The mass spectrum revealed molecular ion peak at m/e: 282 and fragment at m/e: $238\left(\mathrm{M}^{+}-44\right)$ (Fig. 2). No $\mathrm{pK}_{\mathrm{a}}$ value was detected in the aqueous methanol $(1: 1 \mathrm{v} / \mathrm{v})$ solution at $50^{\circ} \mathrm{C}$. Proton NMR $(60 \mathrm{MHz})$ gave peaks $\delta, 7.18(10 \mathrm{H}, \mathrm{s})$, $4.45(1 \mathrm{H}, \mathrm{m}), 3.38(2 \mathrm{H}, \mathrm{s})$ and $3.20-2.60(2 \mathrm{H}, \mathrm{m})$, in parts per million relative to tetramethylsilane $(\delta, 0.00)$. All these data supported 


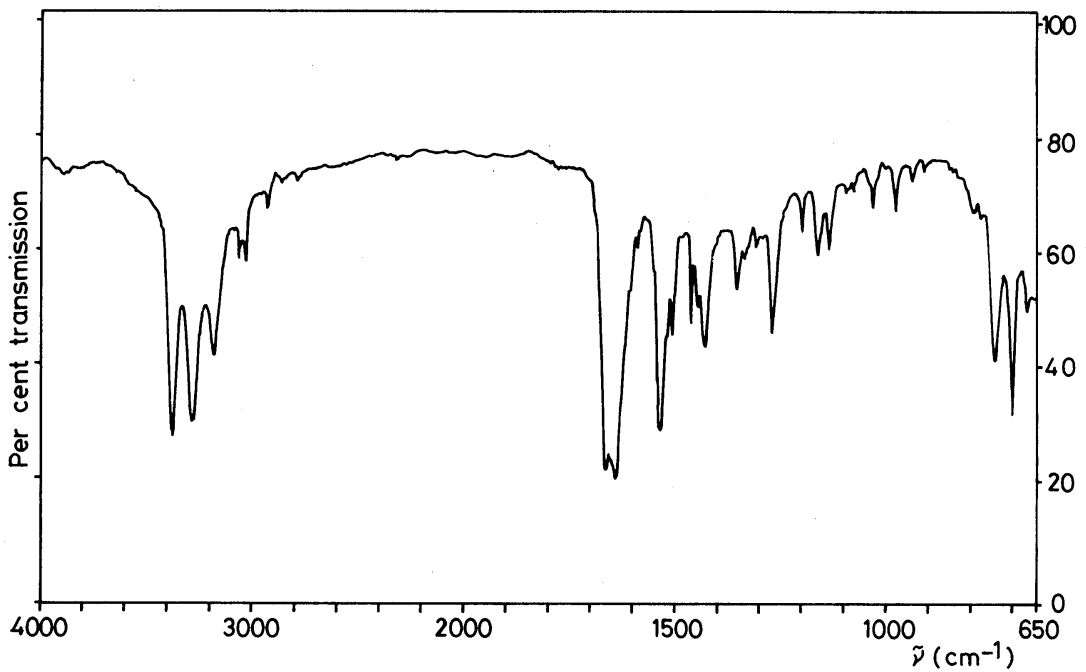

Fig. 1. IR spectrum of the reaction product $(\mathrm{KBr}$ disc).

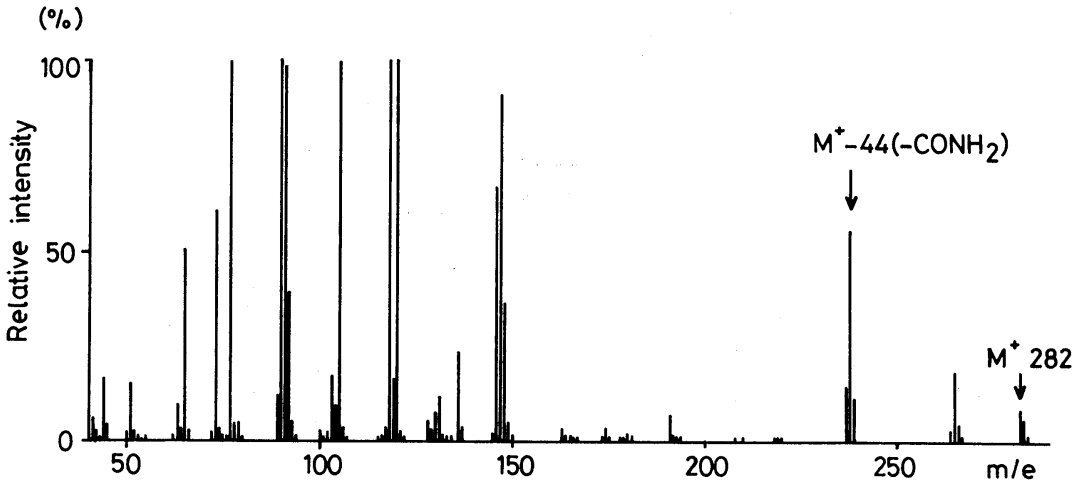

Fig. 2. Mass spectrum of the reaction product.

phenylacetylphenylalanineamide (PPA) was isolated as the reaction product. The formation of this product was confirmed by comparing it with the authentic product prepared by a condensation of phenylacetylphenylalanine (PP), ${ }^{4}$ using ammonia and by mixed examination.

In a series of amino acid synthesis from $\alpha$-keto acid and ammonia, eq. (3) is regarded as the most plausible mechanism. ${ }^{3)}$ Reac-

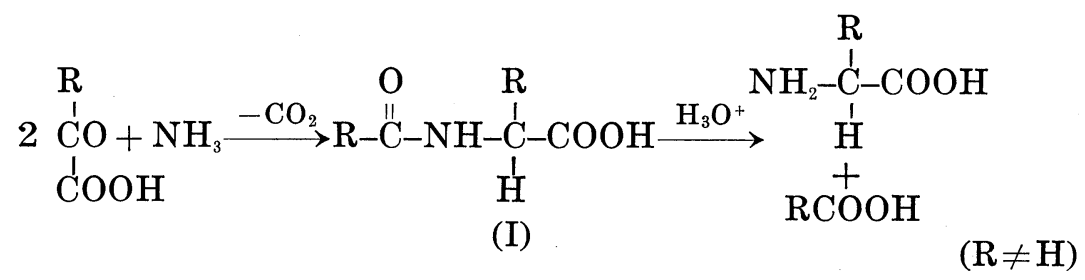


tion intermediates (I) were frequently detected and their hydrolysis gave rise to expected amino acids. A dilute solution of phenylpyruvic acid $(0.15 \mathrm{M})$ and ammonium sulfate $(0.075 \mathrm{M})$ didn't undergo any appreciable precipitation on standing at room temperature after heating for $10 \mathrm{hr}$. One chromatographic analysis of this solution made possible the detection of $\mathrm{PP}$, in addition to PPA (silica gel TLC, $\left.\mathrm{CHCl}_{3}: \mathrm{MeOH}: \mathrm{AcOH}=95: 5: 1\right)$. An attempt to isolate PP from reaction mixture was unsuccessful. The reason for this is that PP may possibly be easily converted to PPA in the reaction mixture. This is supported by the fact that PPA was qualitatively prepared from a PP and ammonium sulfate mixture, and detected by IR. All the information, however, is not inconsistent with eq. (3) and PPA could be separated out from the reaction mixture owing to its low solubility. The entire scheme mentioned above is illustrated in Fig. 3. However, other mechanisms for PPA synthesis may not be excluded completely since PPA spot can be detected on the TLC of a dilute reaction mixture.

The total yield of phenylalanine was calculated to be $15.6 \%$, based on the finding that two moles of phenylpyruvate give one mole of
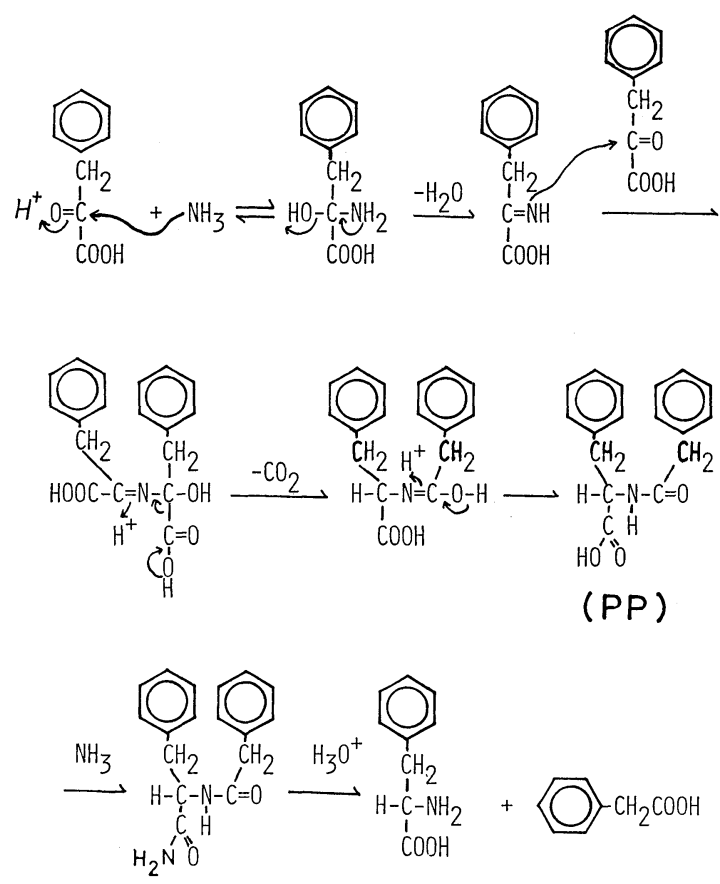

(PPA)

Fig. 3. Plausible reaction pathway. 
final product. This is much better than that of the alanine synthesis in which pyruvic acid was used (yield $3.5 \%$ ). This might be due to the ease of the decarboxylation step owing to the steric hindrance of the $\mathrm{Ph}-\mathrm{CH}_{2}$-residue.

Emphasis should be directed to the most characteristic features of the two kinds of amide bond formations in an aqueous medium without the use of a condensation reagent. In particular, the cascade formation of PPA may provide a new means for overcoming the energy barrier involved in the formation of peptide bonds under prebiotic conditions.

\section{References}

1) H. Hatanaka and F. Egami: Bull. Chem. Soc. Jpn., 50, 1147-1156 (1977).

2) H. Yanagawa, Y. Kobayashi, and F. Egami: J. Biochem., 87, 359-362 (1980).

3) F. Egami, Y. Makino, K. Sato, M. Nishizawa, and H. Yanagawa: Viva Origino, 8, 66-67 (1981).

4) N. Lustig, H. Spiegelstein-Klarfeld, E. Schneider, and N. Lichtenstein: Isr. J. Chem., 12, 757-763 (1974). 